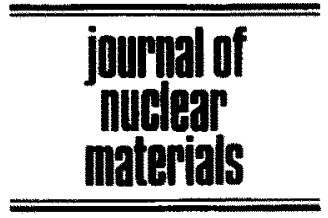

\title{
Quantitative analysis of radiation-induced grain-boundary segregation measurements
}

\author{
R.D. Carter, D.L Damcott, M. Atzmon, G.S. Was \\ Department of Nuclear Engineering, The University of Michigar, Ann Arbor, MI 48109, USA
}

S.M. Bruemmer

Pacific Northwest Laboratory Richland, WA 99352, USA

E.A. Kenik

Metals and Ceramics Division, Oak Ridge National Laboratory, Oak Ridge, TN 37831, USA

Received 25 October 1993; accepted 11 February 1994

\begin{abstract}
Radiation-induced and precipitation-induced grain-boundary segregation profiles are routinely measured by scanning-transmission electron microscopy using energy-dispersive X-ray spectroscopy (STEM-EDS). However, radiation-induced grain-boundary segregation (RIS) profiles achieved at low and moderate temperatures are exceedingly narrow, typically less than $10 \mathrm{~nm}$ full width at half maximum. Since the instrumental spatial resolution can be a significant fraction of this value, the determination of grain boundary compositions poses a formidable challenge. STEM-EDS and Auger electron spectroscopy (AES) measurements are reported, performed on controlled-purity alloys of type 304L stainless steel irradiated with $3.4 \mathrm{MeV}$ protons to 1 displacement per atom at $400^{\circ} \mathrm{C}$. Because of statistical noise and the practical lower limit on the step size in STEM, deconvolution of the measured data does not yield physical results. An alternative analysis of STEM data is presented. Numerical calculations of RIS profiles are convoluted with the instrumental broadening function and modified iteratively to fit the data, yielding a "best estimate" profile. This "best estimate" is convoluted with the Auger intensity profile to yield a simulated AES measurement, which is compared with the actual AES measurement to provide an independent test of the validity of the "best estimate". For impurities with a narrow segregation profile and an Auger electron escape depth of one monolayer, a combination of STEM and AES data allows a determination of the width of the segregated layer. It is found that, in an ultrahigh-purity alloy doped with $\mathbf{P}$, the latter is essentially contained in a single monolayer.
\end{abstract}

\section{Introduction}

Radiation-induced segregation (RIS) is the spatial redistribution of elements at defect sinks during irradiation [1-3]. RIS has been studied in a wide variety of alloys, particularly those with applications in the nuclear power industry [4]. RIS of silicon or phosphorus to grain boundaries $[5,6]$, or the depletion of $\mathrm{Cr}[7]$ at grain boundaries has been suggested as a principal cause of irradiation-assisted stress corrosion cracking
(IASCC). Stress corrosion cracking (SCC) of reactor components becomes enhanced above a critical neutron fluence, and can lead to premature intergranular failure of the component $[4,8,9]$. Indeed, there is evidence that IASCC is a generic problem that is not confined to a particular type of reactor, component or alloy. In his recent review on IASCC [8], Andresen identified 6 alloys used in 17 different reactor core components in 4 reactor types which experienced IASCC in service. As such, IASCC has become one of 


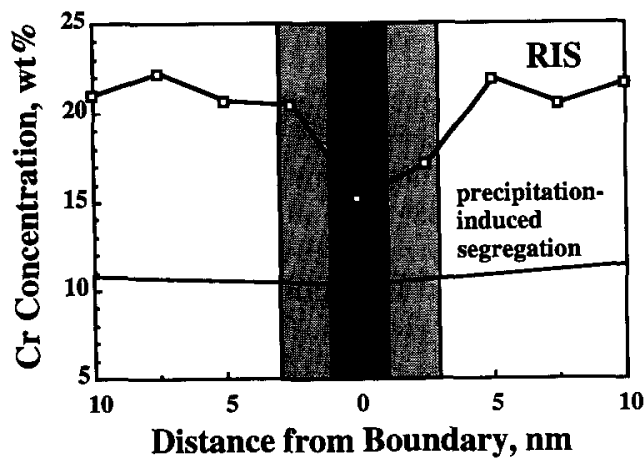

Fig. 1. Diagram illustrating the problems with measuring RIS profiles using STEM. The top $\mathrm{Cr}$ concentration profile is from a neutron-irradiated alloy [12] and is typical of measured RIS profiles. The bottom profile [13] is typical of thermal sensitization profiles. The dark shaded area represents the incident beam diameter and the lighter shaded area the scattered beam diameter upon leaving the bottom of the foil.

the major concerns threatening the integrity of core components in both existing light water reactors (LWRs) and advanced reactor concepts. If indeed RIS plays a role in the IASCC process, then the first step in understanding and solving the problem is the accurate determination of grain-boundary composition profiles in irradiated material. This poses its own set of problems.

Analysis of grain-boundary composition profiles using scanning transmission electron microscopy (STEM) was first applied in the late 1970 s $[10,11]$ to quantify the chromium depletion profiles at grain boundaries in austenitic alloys which had undergone thermal treatments, resulting in the precipitation of chromium carbides at the grain boundaries and chromium depletion in the adjacent matrix. Such analyses were made possible by the development of the STEM with a finely focused electron probe to enable sampling of very small volumes. The analysis of grain boundary segregation due to irradiation is considerably more challenging. Fig. 1 shows a comparison between the width of a chromium depletion profile in 304 stainless steel that underwent thermal sensitization and a similar sample that was neutron irradiated. Note the disparity in the widths of the depleted zones. More importantly, note the width of the depleted zone of the irradiated sample in relation to the incident and scattered electron beam diameter for a typical configuration in a STEM. While the $\mathrm{Cr}$ concentration changes insignificantly over the length scale of the scattered electron beam in the case of the thermally sensitized sample, there is a change in the $\mathrm{Cr}$ concentration in the neutron irradiated sample over the same distance by several atom percent. Clearly, the finite probe width and beam broadening will result in a serious underestimation of the extent of grainboundary chromium depletion.

STEM and Auger electron spectroscopy (AES) are the principal methods of quantifying grain boundary composition. Measurements of RIS using STEM have been performed at Harwell Laboratory, UK [12,14-16] and Pacific Northwest Laboratory using the VG HB501 STEM [17], and at Oak Ridge National Laboratory using a Philips EM400T-FEG STEM $[18,19]$. In both types of microscopes, the minimum incident electron probe diameter is $\sim 2 \mathrm{~nm}$, which is a large fraction of the RIS profile width in neutron irradiated steels. Analysis is performed by directing a finely focused electron beam parallel to a well-aligned grain-boundary plane. The beam is stepped across the boundary and the average composition at each step is determined by energy dispersive $\mathrm{X}$-ray spectrometry (EDS). The result is a grain boundary composition profile which extends into the matrix on either side of the grain boundary. Measurement of grain-boundary composition in a scanning Auger microprobe (SAM) requires intergranular fracture in situ to expose grain boundaries in an ultrahigh vacuum environment where contamination is minimized. Analysis is done obliquely on exposed grain facets and the Auger electron yield can be incorporated to obtain quantitative information on the grain boundary composition. Because analysis is performed on grain-boundary facets located within cracks on the sample surface, sputter depth profiling is usually not possible. Therefore, in contrast to STEM, $A E S$ yields information only at the grain boundary.

The success of either method is critically dependent on both the instrument parameters and the experimental technique. In STEM, errors in measurement can arise due to electron beam broadening in the foil, inaccurate measurement of foil thickness, improper alignment of the grain boundary, insufficient counting time (poor statistics), sample drift during spectrum collection, contamination by surface films, improper accounting for spurious radiation and the lack of a sufficient number of spectra to average over boundaryto-boundary variations in composition. Errors in AES measurements occur due to the overlap of peaks from different elements, insufficient counting time (poor statistics), improper alignment of the grain facet relative to the cylindrical mirror analyzer, improper identification of intergranular (IG) facets, fracture near but not in the grain boundary plane, precipitation of grain boundary phases, unequal distribution of impurities between the two fracture surfaces, sample drift during analysis, lack of a sufficient number of spectra to average over boundary-to-boundary variations in composition and contribution from several atom layers due to the finite Auger electron escape depth. It is not the intent of this paper to address all the sources of error in STEM and AES measurements. Several excellent, 
recent reviews have been written discussing the sources of error in STEM and AES [20-23]. Many of these sources of error are either under the control of the operator, are due to instrument limitations (e.g. mechanical stability which affects drift) or are characteristics of the sample (boundary-to-boundary variation in segregation or the fracture mode). This leaves only two critical factors which can be quantitatively treated in order to optimize the determination of the actual grain-boundary composition. These are the spatial resolution of the electron probe and the number of boundaries measured in order to minimize the effect of boundary-to-boundary variations. While both will be the concern of this paper (and have been treated elsewhere [23]), it is the former which is the main focus of attention.

The purpose of this paper is to identify a method for determining the actual grain boundary composition from measurements, use this method to assess the agreement between STEM and AES measurements and to develop guidelines for measurement of grainboundary composition using STEM and AES (in view of the capabilities and limitations of current analytical instruments) to yield the best estimate of the actual composition. This paper will present the results of measurements using both AES and STEM-EDS to quantify RIS at the grain boundary resulting from proton irradiation at a controlled temperature. Proton irradiation experiments are used because no complimentary AES and STEM analysis exists for neutronirradiated matcrial at this time. Direct measurement of the actual grain-boundary composition is not possible with these techniques, so correction methods including deconvolution and convolution are explored in order to obtain a better estimate of the actual grain-boundary composition. $\Lambda$ technique for determining the distribution of impurity elements at grain boundaries that combines both the AES and STEM measurements is presented. The utility of correction techniques in obtaining the actual grain boundary composition will be discussed and a set of recommendations is presented for the collection and analysis of data using STEM and AES to optimize the quantitative determination of the actual grain-boundary composition.

\section{Experiment}

Four controlled-purity alloys of type 304L stainless steel have been examined: an ultrahigh purity alloy (UHP) and UHP alloys containing additions of 0.03 at $\%$ sulfur (UHP $+\mathrm{S}), 0.08$ at $\%$ phosphorus (UHP + $\mathrm{P}$ ), or 0.87 at \% silicon (UHP + Si). The base compositions of these alloys, as determined by electron microprobe analysis, are given in Table 1 . The as-received alloys were solution annealed at $1100^{\circ} \mathrm{C}$ for $1 \mathrm{~h}$ to homogenize the microstructure, and were then coldrolled to $2 \mathrm{~mm}$ thickness. Samples for irradiation were cut from the rolled material for both AES $(2 \mathrm{~mm} \times 2.5$ $\mathrm{mm})$ and TEM ( $4 \mathrm{~mm} \times 2 \mathrm{~mm})$ analysis. These samples were wet polished with silicon carbide paper and given a 0.5 to $1 \mathrm{~h}$ recrystallization anneal at $850^{\circ} \mathrm{C}$ to achieve a grain size of approximately $10 \mu \mathrm{m}$. After annealing the samples were again wet polished and electropolished in a $60 \%$ phosphoric $+40 \%$ sulfuric acid solution at $-50^{\circ} \mathrm{C}$ to provide a smooth surface finish prior to irradiation. Samples for Auger analysis were notched on one side to a depth of $0.5 \mathrm{~mm}$.

Samples for AES and STEM analyses were irradiated with $3.4 \mathrm{MeV}$ protons to $1 \mathrm{dpa}$ at $400^{\circ} \mathrm{C}$, with a dose rate of approximately $7.0 \times 10^{-6} \mathrm{dpa} / \mathrm{s}$ on a specially designed irradiation stage in a vacuum $<2.0$ $\times 10^{-8}$ Torr. Irradiation of stainless steel with 3.4 $\mathrm{MeV}$ protons produces a region of nearly uniform damage over the first $35 \mu \mathrm{m}$ of the proton range [24]. The $400^{\circ} \mathrm{C}$ irradiation temperature was chosen to provide elemental composition profiles similar to those obtained in LWR core components at $288^{\circ} \mathrm{C}$. A thin layer of molten tin between the samples and the stage was used to achieve good thermal control. The temperature was controlled by simultaneous resistive heating and cooling using flowing water or forced air. The sample surface temperature was monitored by a calibrated infrared pyrometer and was maintained at 400 $\pm 10^{\circ} \mathrm{C}$. Following irradiation, the proton-induced residual activity decayed to near-background levels in approximately $72 \mathrm{~h}$, allowing for safe sample handling and analysis without interference from background radiation. Details of the irradiation technique and comparison of the proton-irradiated microstructure and

Table 1

Bulk alloy compositions as determined by electron microprobe analysis (at $\%$ )

\begin{tabular}{lllllllll}
\hline Alloy & Cr & Ni & Mn & Al & S & P & Si & Fe $^{\text {a }}$ \\
\hline UHP & 20.72 & 8.88 & 1.11 & 0.02 & ND & 0.01 & 0.09 & 69.17 \\
UHP + P & 21.02 & 8.68 & 1.15 & ND & ND & 0.08 & 0.03 & 69.04 \\
UHP + S & 20.91 & 8.94 & 1.04 & ND & ND & ND & 0.03 & 69.08 \\
UHP + Si & 20.41 & 8.55 & 1.34 & ND & ND & ND & 0.87 & 68.83 \\
\hline
\end{tabular}

$\mathrm{ND}=$ Element was not detected in electron microprobe analysis.

${ }^{a} \mathrm{Fe}$ concentration such that sum of all elements $=100 \%$.

blement not detected in analysis, nominal composition 0.03 at $\%$. 


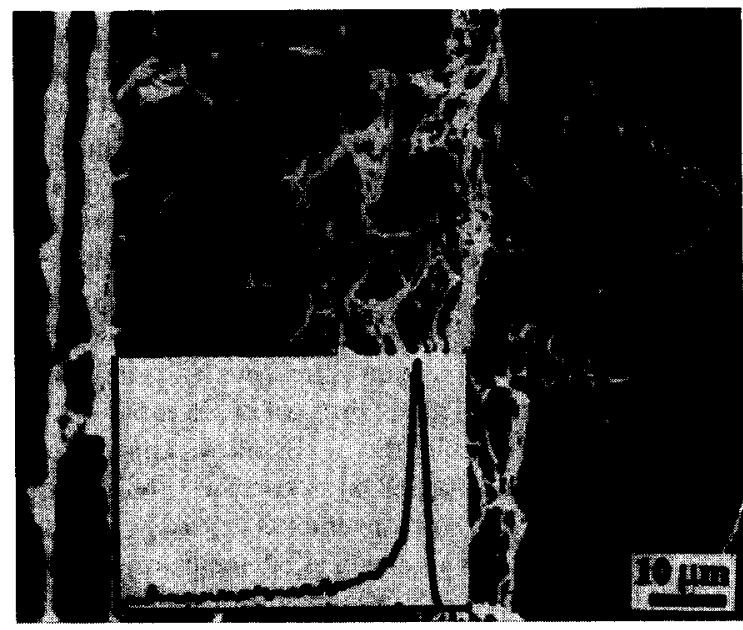

Fig. 2. Typical fracture surface achieved in the SAM after hydrogen charging and slow bending of a UHP $+S$ sample to open intergranular cracks. Overlay shows the damage profile induced by proton irradiation extending to the depth of the intergranular fracture.

segregation with that following neutron irradiation are described elsewhere [19,25].

Following irradiation, samples for AES analysis were cathodically charged with hydrogen, according to the procedure described by Briant [26], to promote intergranular fracture upon loading. The samples were fractured in situ in a Perkin Elmer (PHI) 660 SAM at approximately $0^{\circ} \mathrm{C}$ by slowly bending the sample at the notch to $\sim 40^{\circ}$ over a duration of approximately $7 \mathrm{~min}$. Grain facets selected for analysis were evaluated using several criteria: sharp-edges, absence of surface features, absence of striations, a size of at least $5 \mu \mathrm{m}$ and a location at least one grain diameter $(\sim 10 \mu \mathrm{m})$ from the sample surface. An example of a fracture surface from the UHP $+S$ alloy is shown in Fig. 2.

Survey spectra of intensity as a function of Auger electron energy were collected from several exposed grain boundary facets by surveying all Auger energies from 0 to approximately $2100 \mathrm{eV}$ to identify the species present. Compositional analysis of grain boundaries was conducted using the multiplex option on the SAM to scan only the energy intervals of the elemental peaks of interest. The elements used for multiplex analysis were iron, chromium, and nickel for all alloys, and also phosphorus in the UHP + P samples and sulfur in the $\mathrm{UHP}+\mathrm{S}$ samples. Contamination by carbon and oxygen was monitored during acquisition by including their elemental peaks in the multiplexed acquisitions. Data collection was terminated when carbon and oxygen peaks became distinguishable from background noise, having concentrations estimated to be less than 5 at\%.
This is particularly critical as a strong oxygen signal can interfere with the chromium signal because the two elements have Auger electrons of nearly the same energy. Due to constraints on the collection time caused by contamination, data were obtained for only the most prominent Auger transitions. All spectra were collected at pressures of less than $7.0 \times 10^{-9}$ Torr using a beam voltage of $10 \mathrm{kV}$ with an electron beam current of $5 \mathrm{nA}$. The atomic concentration calculation routine in the SAM operating software was used to convert the intensity to atomic concentration following the procedure given in Ref. [27]. The number of grain boundaries analyzed for each alloy was fixed by the requirement that the standard deviation of the mean value be less than $\sim 0.5$ at\%. This typically required 30 grain boundaries from several (5-7) samples spanning multiple irradiations.

Three-millimeter disk samples for STEM analysis were cut from the $4 \mathrm{~mm}$ wide irradiated bars using a slurry drill core cutter to minimize deformation. The disks were mechanically back-thinned by grinding with wet $\mathrm{SiC}$ paper (400 grit) to approximately $100 \mu \mathrm{m}$ thickness. Disks were then jet-thinned to electron transparency using a solution of $20 \mathrm{vol} \%$ perchloric acid in ethanol at a constant voltage of $120 \mathrm{~V}$ and a temperature of $-55^{\circ} \mathrm{C}$.

Measurement of grain boundary composition by STEM was performed at Oak Ridge National Laboratory on a Philips EM400T/FEG operated in STEM mode and equipped with an EDAX 9100/70 EDS system. A double-tilt, liquid-nitrogen-cooled specimen holder was used for microanalysis to minimize contamination of the sample in the focused beam [28]. EDS analysis was performed using an incident probe of 2 $\mathrm{nm}$ diameter (full width, tenth maximum) in regions of sample thickness less than $75 \mathrm{~nm}$. Grain boundaries were aligned parallel to the incident electron beam. Multiple measurements were made at numerous grain boundaries for each alloy. The number of measurements was governed by the same requirement of the standard deviation of the mean as in AES analysis. This usually required $15-20$ grain boundary measurements. At least 2 complete grain boundary profiles from each alloy were acquired by taking a series of spot analyses across the boundary at preset distances normal to the boundary. Data acquisition lasted $100 \mathrm{~s}$ with count rates of about $75 \mathrm{c} / \mathrm{s}$ for the smallest peak (among $\mathrm{Fe}, \mathrm{Cr}$ and $\mathrm{Ni}$ ) providing a statistical error of $\sim 1 \%$. Subtraction of "in-hole" spectra from the measured spectra was performed to correct for uncollimated radiation from the microscope illumination system and radiation associated with the residual radioactivity of the sample. Collected raw intensity data were converted to weight and atomic concentrations using $k$-factors [29] calculated from comparison of EDS-determined matrix intensities to the bulk alloy composi- 
tion determined independently by electron microprobe analysis, Table 1.

\section{Results}

A summary of the grain boundary measurements for each of the alloys, as determined by STEM and AES, is presented in Table 2. In the UHP alloy, STEM-EDS measurements of the grain boundary composition reveal depletion of $\mathrm{Cr}$ to 17.2 at \% and enrichment of $\mathrm{Ni}$ to 11.0 at \%. As is the case in all the alloys, the $\mathrm{Cr}$ profile is wider than the $\mathrm{Ni}$ profile by $2-3 \mathrm{~nm}$, with average full widths at half maximum (fwhm) of 6-9 $\mathrm{nm}$ for $\mathrm{Cr}$ profiles and 4-7 $\mathrm{nm}$ for Ni profiles. The measured segregation profiles for all of the alloys are shown in Figs. 3a-3d for the UHP, UHP $+\mathrm{P}, \mathrm{UHP}+\mathrm{S}$ and $\mathrm{UHP}+\mathrm{Si}$ alloys respectively. The two profiles providing the best agreement with the mean grain boundary value are presented for each alloy. Greater degrees of $\mathrm{Cr}$ and $\mathrm{Ni}$ segregation arc observed in the $\mathrm{UHP}+\mathrm{P}$ and $\mathrm{UHP}+\mathrm{S}$ alloys than are found in the UHP alloy, possibly indicating a synergism between radiation induced segregation and the presence of impurities. Phosphorus enrichment to 1.4 at $\%$ is measured in the grain boundary of the UHP $+\mathbf{P}$ alloy, but no $\mathrm{S}$ segregation is detected in the UHP $+\mathrm{S}$ alloy. The $\mathrm{Cr}$ concentration at the boundary drops to 16.5 at $\%$ in the $U H P+P$ alloy and to 16.1 at $\%$ in the UHP $+S$ alloy, and the $\mathrm{Ni}$ concentration increases to $\sim 12.0$ at $\%$ in both alloys. The segregation profiles for these elements are significantly wider and deeper than those in the UHP alloy. The UHP + Si alloy showed by far the most segregation at boundaries, with the $\mathrm{Cr}$ concentration dropping to 14.4 at $\%, \mathrm{Ni}$ enriching to 13.1 at $\%$, and $\mathrm{Si}$ enriching to 3.2 at $\%$. The segregation profiles are slightly wider than those found in the $\mathrm{UHP}+\mathrm{P}$ and $\mathrm{UHP}+\mathrm{S}$ alloys.
Significant RIS is measured by AES in the irradiated UHP, UHP $+S$, and UHP $+P$ alloys. Because intergranular fracture is not achieved in the UHP $+\mathrm{Si}$ alloy, grain boundary AES measurements are not possible. For consistency, the bulk composition is used as a reference for determining the relative amounts of grain boundary segregation for all alloys. As significant thermal segregation of major elements is not expected at $400^{\circ} \mathrm{C}[30,31]$, any changes in grain boundary composition of the irradiated alloys are thus assumed to be due to irradiation. The results of AES analysis are included in Table 2. In the UHP alloy, chromium is depleted to 17.2 at $\%$ while $\mathrm{Ni}$ is enriched to 12.9 at \%, compared to STEM measurements of 17.2 and 11.0 at\%, respectively. As in the STEM measurement, the $\mathrm{UHP}+\mathrm{P}$ and $\mathrm{UHP}+\mathrm{S}$ alloys show more dramatic redistribution of $\mathrm{Cr}$ and $\mathrm{Ni}$ at the grain boundaries after irradiation. The $\mathrm{Cr}$ concentrations in both alloys drop to $\sim 15.0$ at $\%$ at the boundary. Nickel is enriched from 8.9 to 15.5 at \% and from 8.7 to 13.8 at $\%$ in the UHP $+S$ and UHP + P alloys, respectively. Phosphorus enrichment at the grain boundary to an average level of 8.7 at $\%$ is observed in the irradiated UHP $+\mathrm{P}$ alloy. This value is 1.6 times the grain boundary concentration measured in the unirradiated material and 100 times the bulk value of 0.08 at\%. (Grain boundary enrichment of $\mathrm{P}$ in the unirradiated UHP $+\mathrm{P}$ alloy occurs during heat treating for grain size control.) No enrichment of sulfur is measured at the boundaries of the irradiated UHP $+S$ alloy, consistent with previous observations [8] and current STEM results. The fact that $\mathrm{S}$ is not observed to segregate at the boundary indicates that large quantities of impurities need not segregate for increased $\mathrm{Cr}$ and $\mathrm{Ni}$ redistribution to occur. Further details of the AES analyses and results are presented elsewhere [19].

All of the irradiated alloys show significant depletion of $\mathrm{Cr}$ and enrichment of $\mathrm{Ni}$ at the grain boundary

Table 2

Summary of AES and STEM measurements of grain-boundary composition in the irradiated alloys (at\%). Errors are given as the standard deviation of the mean, $\sigma / \sqrt{N} . \mathrm{ND}=$ not detected

\begin{tabular}{|c|c|c|c|c|c|c|c|c|}
\hline Alloy & $\begin{array}{l}\text { Number of } \\
\text { measurements } \\
N\end{array}$ & $\begin{array}{l}\text { Number of } \\
\text { samples }\end{array}$ & $\mathrm{Fe}$ & $\mathrm{Cr}$ & $\mathrm{Ni}$ & $\mathrm{P}$ & $S$ & $\mathrm{Si}$ \\
\hline \multicolumn{9}{|l|}{$\overline{\mathrm{UHP}}$} \\
\hline AES & 31 & 5 & $69.9 \pm 0.7$ & $17.2 \pm 0.7$ & $12.9 \pm 0.3$ & ND & ND & ND \\
\hline STEM & 26 & 2 & $71.8 \pm 0.1$ & $17.2 \pm 0.2$ & $11.0 \pm 0.2$ & ND & ND & ND \\
\hline \multicolumn{9}{|l|}{$\mathrm{UHP}+\mathrm{P}$} \\
\hline AES & 34 & 7 & $62.5 \pm 0.7$ & $15.0 \pm 0.4$ & $13.8 \pm 0.5$ & $8.7 \pm 0.4$ & ND & $\mathrm{ND}$ \\
\hline STEM & 14 & 1 & $70.2 \pm 0.3$ & $16.5 \pm 0.4$ & $11.9 \pm 0.3$ & $1.4 \pm 0.1$ & ND & ND \\
\hline \multicolumn{9}{|l|}{$\mathrm{UHP}+\mathrm{S}$} \\
\hline AES & 42 & 5 & $69.3 \pm 0.5$ & $15.0 \pm 0.5$ & $15.5 \pm 0.5$ & ND & ND & ND \\
\hline STEM & 18 & 1 & $71.4 \pm 0.1$ & $16.1 \pm 0.2$ & $12.0 \pm 0.2$ & ND & ND & ND \\
\hline \multicolumn{9}{|l|}{$\mathrm{UHP}+\mathrm{Si}$} \\
\hline STEM & 21 & 1 & $69.3 \pm 0.2$ & $14.4 \pm 0.2$ & $13.1 \pm 0.2$ & ND & ND & $3.2 \pm 0.1$ \\
\hline
\end{tabular}


by both AES and STEM. In addition, both techniques show that depletion of $\mathrm{Cr}$ and enrichment of $\mathrm{Ni}$ is consistently greater in the UHP $+\mathrm{P}$ and $\mathrm{UHP}+\mathrm{S}$ alloys than is found in the UHP alloy, with STEM confirming this trend for the UHP $+\mathrm{Si}$ alloy. Fig. 4 graphically compares the major element segregation measured using the two techniques. In all cases, the same trends in the segregation behavior are reflected in both sets of data with AES revealing as much or more depletion or enrichment at the boundary as



(a)
STEM. The greatest disparity between AES and STEM is observed in the measurements of $P$ segregation. In AES, 8.7 at \% P was measured at the grain boundary, while in STEM 1.4 at \% was detected. As with the major element compositions, this is likely due to differences in resolution between AES and STEM, with AES being much more sensitive to near-monolayer profile width. While Si segregation in the UHP + Si alloy was measured in STEM to levels more than twice that of $P$ in the UHP $+P$ alloy, the accuracy of the Si

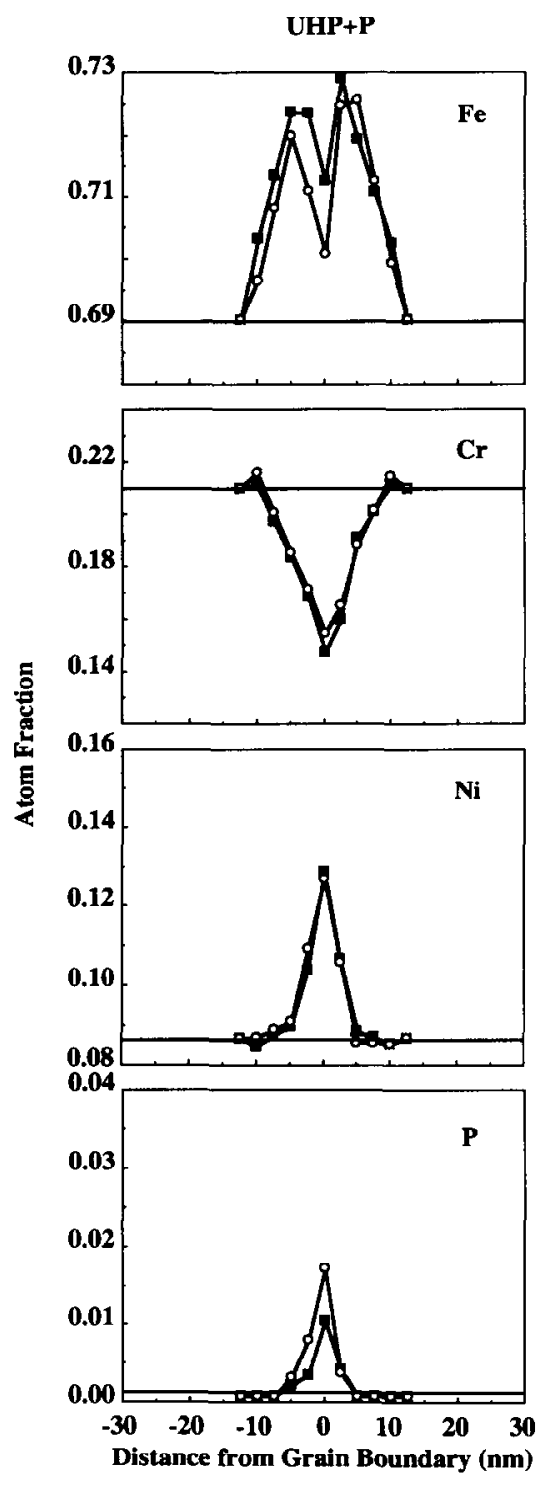

(b)

Fig. 3. Composition profiles as measured using STEM for $\mathrm{Fe}, \mathrm{Cr}, \mathrm{Ni}$ and any impurity elements included: (a) UHP alloy; (b) UHP + P alloy with P profile; (c) UHP + S alloy, in which no S was measured; (d) UHP + Si alloy with Si profile. The horizontal line in each graph denotes the hulk concentration of the element. 
measurements by STEM is uncertain in light of the large differences between STEM and AES for P. The nature of Si segregation may be significantly different than that for $\mathrm{P}$ given the higher bulk concentration of $\mathrm{Si}$ and the apparent existence of a measurable segregation profile [19].

\section{Analysis of results}

The focus of the analysis will center around the feasibility of determining the actual grain-boundary

UHP+S

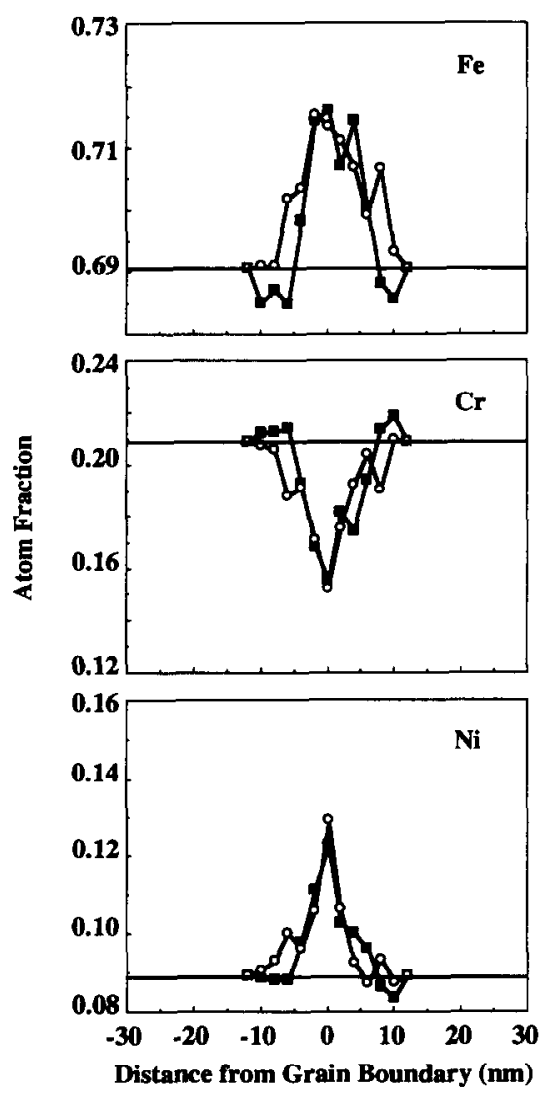

(c) concentration of specific alloying elements based on AES and STEM measurements. A critical analysis of deconvolution is made in which it will be shown why this method is not expected to succeed in this application. It will also be shown that convolution of computed profiles with the $\mathrm{X}$-ray generation function provides a much better estimate of the actual composition profile. Application of the results of convolution to obtain a comparison between STEM results and AES measurements will follow. Finally, an analysis of impurity element segregation will be presented.

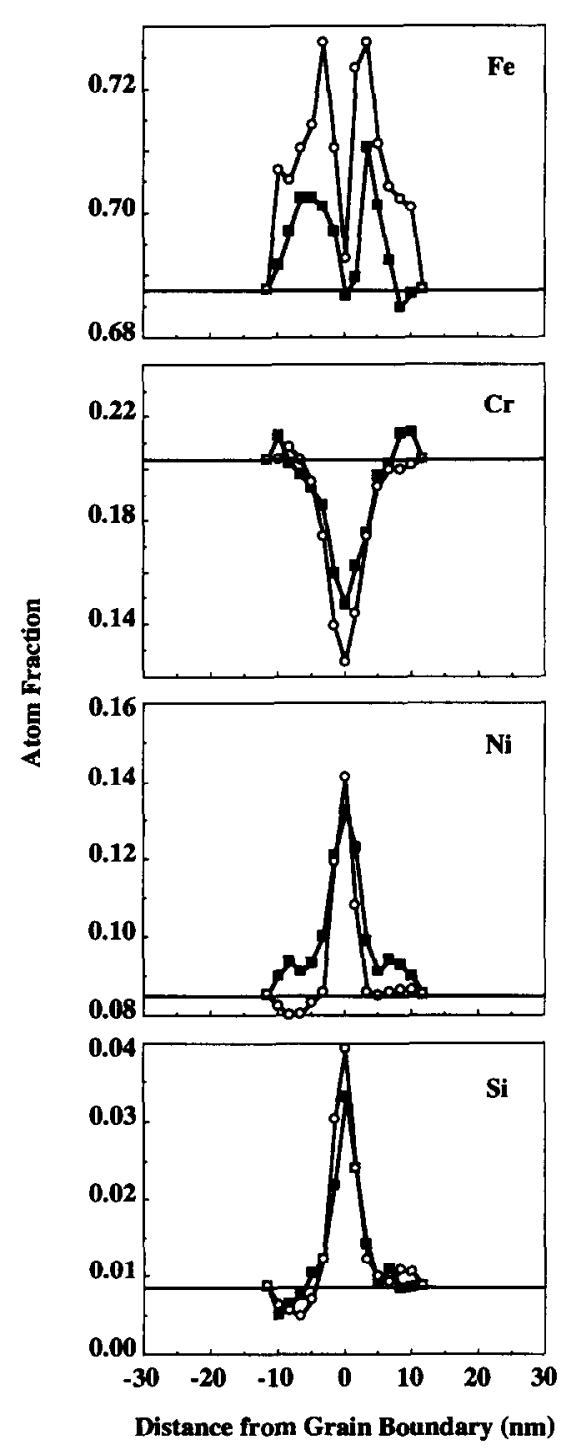

(d)

Fig. 3 (continued). 


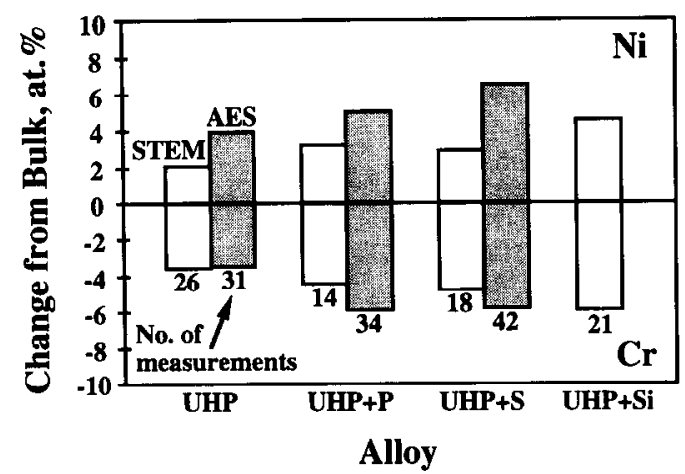

Fig. 4. Comparison of the $\mathrm{Cr}$ and $\mathrm{Ni}$ composition changes at the grain boundary in atomic percent, as measured by AES and STEM in the UHP, UHP $+\mathrm{P}, \mathrm{UHP}+\mathrm{S}$, and $\mathrm{UHP}+\mathrm{Si}$ alloy. The change in nickel concentration is above the $0 \%$ line, and the change in chromium concentration is below the $0 \%$ line. Note: AES data is not available for the UHP+Si alloy (see text)

\subsection{Deconvolution of measured STEM profiles}

STEM-EDS measurements consistently underestimate the amount of segregation at the grain boundary, mainly because of the finite probe size and of the broadening of the incident electron beam. These two effects result in spatial averaging of the composition over a volume which extends far beyond the boundary region. The goal is to obtain the actual grain-boundary segregation profile by removing the beam averaging effects from the measured grain-boundary profiles. Deconvolution is the process of undoing the smearing in the data which has occurred due to scattering of electrons in the beam-interaction volume in the foil, and can be understood by describing the inverse process of convolution.

The measured composition profile is a result of the convolution of the actual grain-boundary composition profile with the broadened electron beam as it traverses the thickness of the foil. More precisely, it is the convolution of the actual grain-boundary profile with the $\mathrm{X}$-ray generation function. This process can be described mathematically [32] as

$(g * h)(x) \equiv \int_{-\infty}^{\infty} g\left(x^{\prime}\right) h\left(x-x^{\prime}\right) \mathrm{d} x^{\prime}$,

where $x$ is the distance from the grain boundary, $(g * h)(x)$ is the measured (or convoluted) profile, $g\left(x^{\prime}\right)$ is the X-ray generation function averaged over the two spatial dimensions corresponding to the grain boundary plane, and $h(x)$ is the actual grain-boundary composition profile. This can be difficult to calculate; however, this relation is greatly simplified by Fourier transformation, giving,

$F(g * h)=F(g) \cdot F(h)$.

Here, the Fourier transform of the convoluted profile $F(g * h)$, is simply the product of the Fourier transform of the X-ray generation function, $F(g)$ and that of the actual composition profile, $F(h)$. The reverse process, deconvolution, is straightforward - the Fourier transform of the measured (convoluted) profile is divided by that of the $\mathrm{X}$-ray generation function to obtain the Fourier transform of the actual composition profile. More detailed descriptions of the theory behind convolution and deconvolution can be found elsewhere $[32,33]$.

The X-ray generation function was determined from a Monte Carlo simulation of electron-solid interactions [34]. The inputs to the simulation include material parameters such as atomic weight, atomic number, sample density, the initial electron beam intensity profile and sample thickness. Measurement of the electron distribution within the incident beam indicates that the beam is nearly Gaussian in shape with a full width at tenth maximum of $\sim 2.0 \mathrm{~nm}$. The thickness of analyzed regions in STEM is determined first through a known beam current/sample thickness / X-ray intensity relationship which has been empirically determined on samples of similar composition in the Philips EM400T-FEG/STEM. More accurate determinations are made later at the same locations using convergent beam electron diffraction methods [35]. An accuracy of $\pm 10 \%$ of the thickness is readily achieved, which will not significantly affect beam broadening in typical foils. The resulting average $\mathrm{X}$-ray generation function is shown in Fig. 5.

The deconvolution technique was applied to measured $\mathrm{Cr}$ and $\mathrm{Ni}$ grain boundary profiles that were

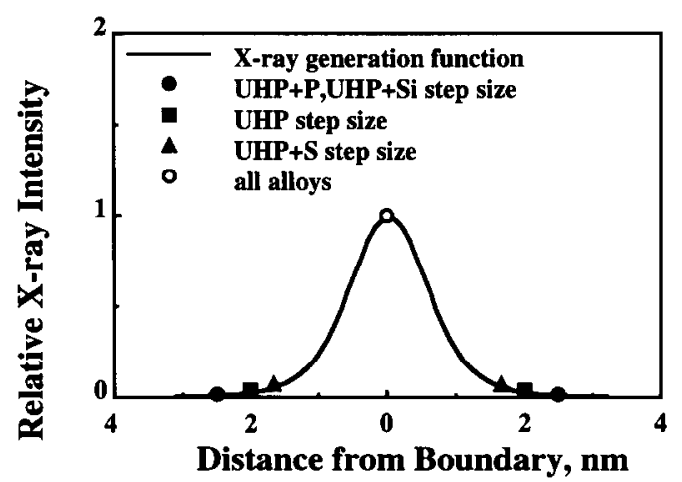

Fig. 5. X-ray generation function in a foil of $\sim 50 \mathrm{~nm}$ thickness. The symbols represent the distance at which the first data point to either side of the grain boundary is measured. All of the alloys have a measurement at the grain boundary as well. 
Table 3

Comparison of STEM-EDS measurements with simulated grain-boundary values

\begin{tabular}{|c|c|c|c|c|}
\hline Alloy & $\begin{array}{l}\text { Step size } \\
(\mathrm{nm})\end{array}$ & $\begin{array}{l}\text { STEM } \\
\text { measurement a }\end{array}$ & $\begin{array}{l}\text { G.B. value from } \\
\text { deconvolution } \\
\text { of STEM } \\
\text { measurement }\end{array}$ & $\begin{array}{l}\text { "Best estimate" } \\
\text { G.B. value }\end{array}$ \\
\hline \multicolumn{5}{|l|}{$\overline{\mathrm{UHP}}$} \\
\hline $\mathrm{Cr}$ & 2.0 & 17.1 & 15.8 & 15.6 \\
\hline $\mathrm{Ni}$ & 2.0 & 11.3 & 12.2 & 14.0 \\
\hline \multicolumn{5}{|c|}{$\mathrm{UHP}+\mathrm{P}$} \\
\hline $\mathrm{Cr}$ & 25 & 15.5 & 14.2 & 13.3 \\
\hline $\mathrm{Ni}$ & 2.5 & 12.7 & 13.4 & 15.7 \\
\hline \multicolumn{5}{|c|}{$\mathrm{UHP}+\mathrm{S}$} \\
\hline $\mathrm{Cr}$ & 1.7 & 15.6 & 16.8 & 12.9 \\
\hline $\mathrm{Ni}$ & 1.7 & 12.3 & 11.2 & 13.5 \\
\hline \multicolumn{5}{|c|}{$\mathrm{UHP}+\mathrm{Si}$} \\
\hline $\mathrm{Cr}$ & 2.5 & 14.7 & 13.3 & 10.8 \\
\hline $\mathrm{Ni}$ & 2.5 & 13.3 & 14.2 & 17.2 \\
\hline
\end{tabular}

${ }^{a}$ Average of grain-boundary values from full composition profiles for each alloy. These differ slightly form the values in Table 2 which are averages of all measurements at the grain boundary.

representative of the average grain boundaries in each of the four alloys. The fast Fourier transform was used in the calculations. Results of deconvolution of these profiles are summarized in column 4 of Table 3 for comparison with experimental results given in column 3 . Note that the measurements are the averages of the grain-boundary values for the full profiles for each alloy, and hence, differ from that reported in Table 2 which are the averages for all grain-boundary measurements. In each case, except for the UHP $+S$ alloy, deconvolution results in an adjustment of the grainboundary value toward more segregation. The most important point to note about these results is that the amount of change in the grain-boundary value by deconvolution is directly related to the size of the step relative to the profile width. For the $\mathrm{Cr}$ profile in the $\mathrm{UHP}+\mathrm{P}$ alloy, Fig. 6 , the difference between deconvoluted and measured profiles is small. This is because the measurements closest to the boundary were on the "tail" of the X-ray generation function at the grain boundary and hence, contributed little to the correction at the grain boundary, Fig. 5. This illustrates one of the most important results from the deconvolution analysis: for any two measurements, even on the same sample and same grain boundary, the step sizes used in the measurements must be identical to provide a meaningful comparison between the deconvolutions. If the step sizes are not identical, deconvolution will always predict greater changes in the profiles with the more closely spaced data points. This is shown in Fig. 7,
$\mathbf{U H P}+\mathbf{P}$

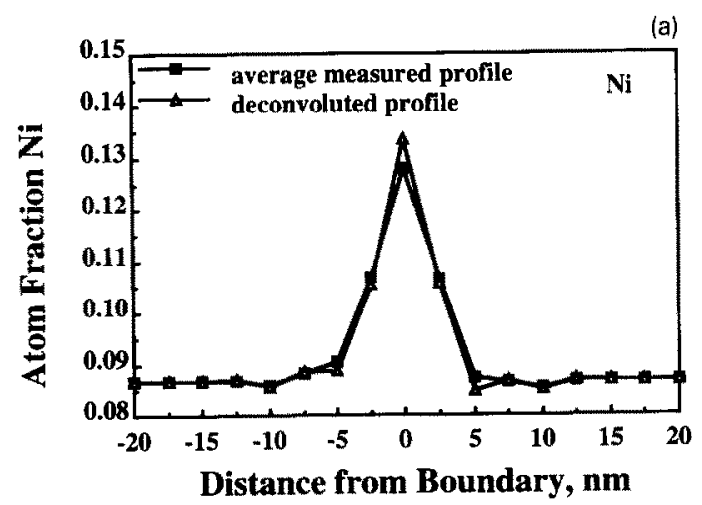

$\mathbf{U H P}+\mathbf{P}$

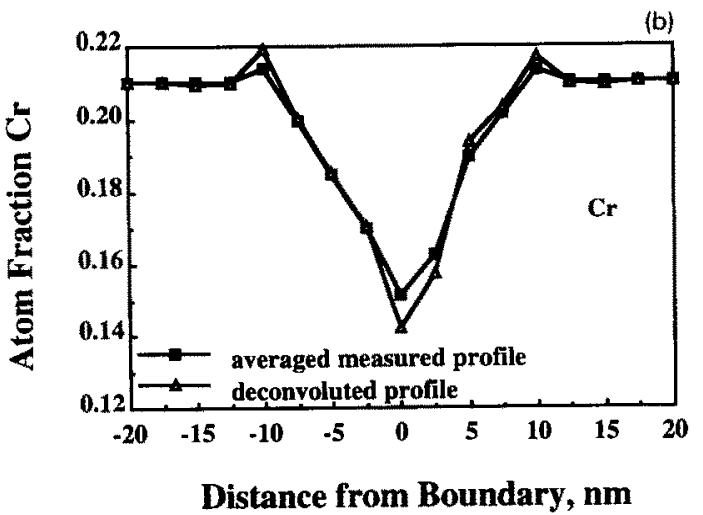

Fig. 6. Measured and deconvoluted profiles for (a) $\mathrm{Ni}$ and (b) $\mathrm{Cr}$ in the UHP $+\mathrm{P}$ alloy, illustrating the minor effect that deconvolution has on the measured profile due to a large step size relative to the $\mathrm{X}$-ray generation function. 


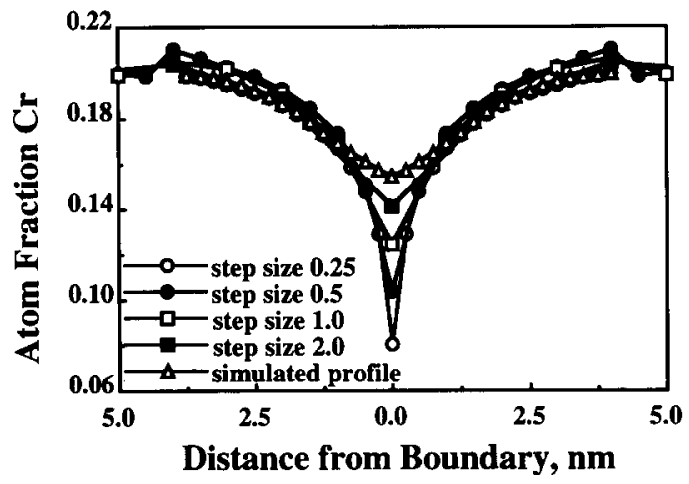

Fig 7. Effect of step size on deconvolution of a simulated grain-boundary profile. Step sizes used in the deconvolution were $0.25,0.5,1$, and $2 \mathrm{~nm}$. Also shown is the simulated profile which was used for deconvolution.

which is a comparison of deconvolution results for the same profile using different step sizes. Note that as the step size becomes smaller, the correction to the grainboundary value becomes larger. This means that deconvolution of a discretely measured function, using the fast Fourier transform, docs not provide a unique solution. One may suggest deconvolution as a means of arriving at a grain-boundary value that is closer to the actual value than the measurement. However, such a result is not consistently obtained because of the noise (scatter) in the individual data measurements themselves, which makes deconvolution impractical for the present problem.

If the measured composition profiles were exact and did not contain any error, then, assuming the $\mathrm{X}$-ray generation function is known, the actual composition profile can be determined by deconvolution. However, the presence of noise introduces substantial difficulties [22]. For a given width, $\Omega$, of the X-ray generation function, $g(x)$, any measured profile width must be greater or equal to $\Omega$. Hence, there is no real function which, upon convolution with the X-ray generation function, would yield the noisy, measured profile, with its narrow features. Therefore, the deconvolution of noisy data cannot yield a correct mathematical solution.

In many applications, filtering of the measured data can alleviate this problem. However, in the present case, the spacing between data points is similar to the width of the actual profile, so that any filtering of the noise would also significantly modify the contribution of the actual profile. As an example, we show the results of the deconvolution of simulated, noisy, data. A computer-generated composition profile was convoluted with the average $\mathrm{X}$-ray generation function to create a simulated measured profile, which was then deconvoluted, Fig. 8a. The simulated profile then had random perturbations of various magnitudes added to each data point to simulate typical noise in the measured data, and the resulting profile was deconvoluted. Fig. 8b shows the effect of randomly adding up to \pm 0.5 at $\%$ to each data point and then deconvoluting the profile. The large high frequency oscillations result in
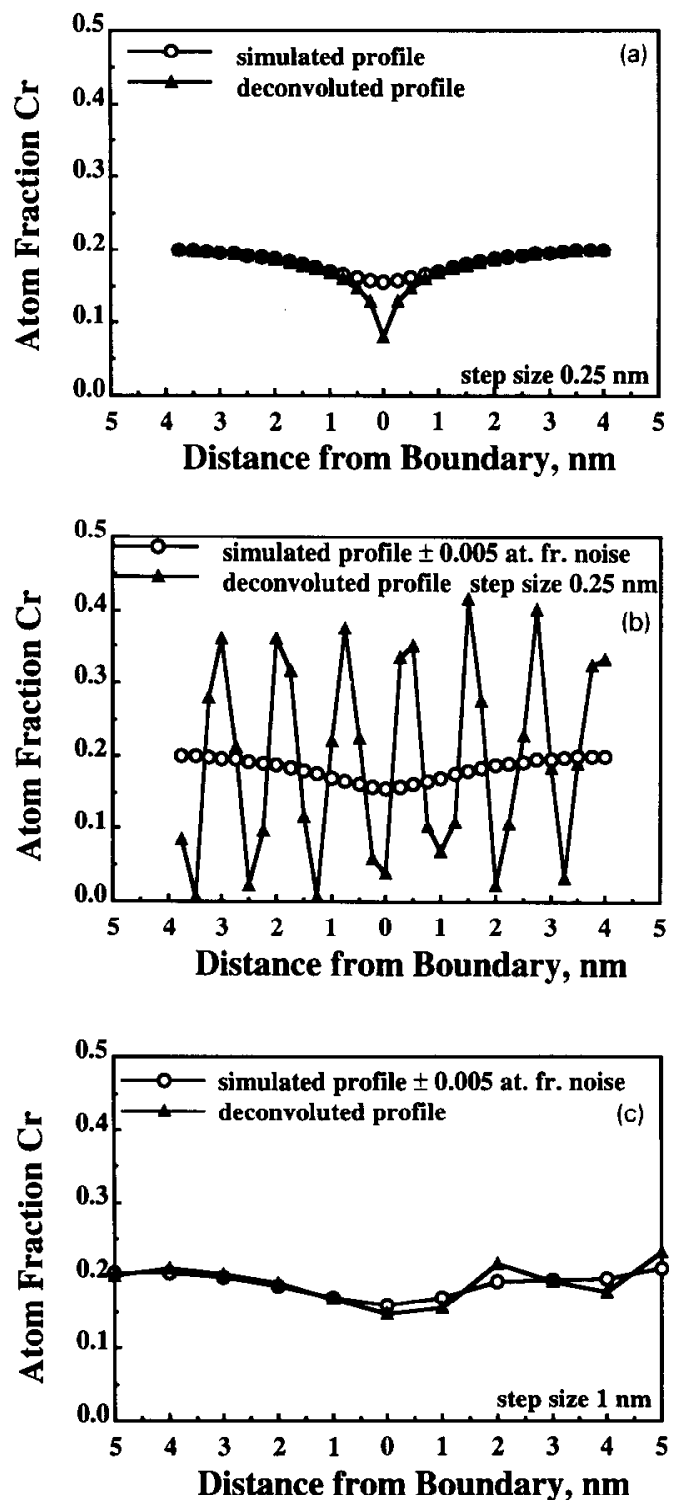

Fig 8. Effect of noise on simulated grain-boundary profiles: (a) simulated profile and deconvolution of this profile; (b) the same profile as in (a) but with up to \pm 0.005 atom fraction noise added to the simulated profile before deconvolution to illustrate the effect of scatter in the data on the deconvolution. The step size in (a) and (b) is $0.25 \mathrm{~nm}$. (c) Same profile as in (a) but with a step size of $1 \mathrm{~nm}$, illustrating the decreased sensitivity to noise with wider step spacing. 


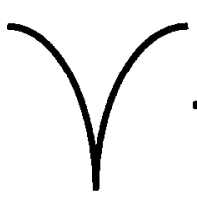

Profile Calculated from Code

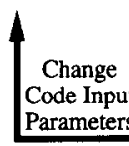

(a)



$X$-ray intensity profile

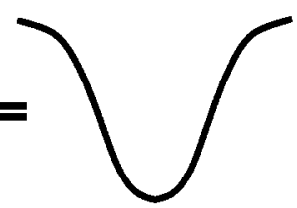

Simulated STEM Profile

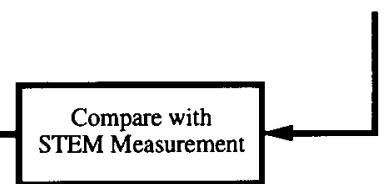

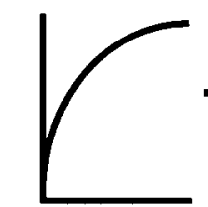

"Best Estimate" of True Profile Calculated (b)

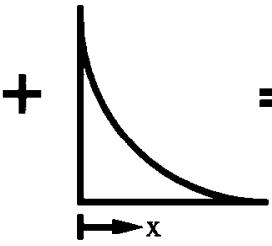

Auger Electron Intensity Profile

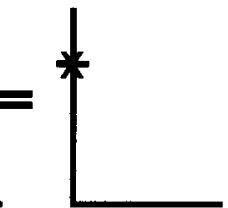

Simulated AES Value

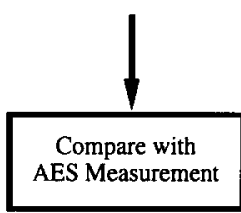

Fig. 9. (a) Schematic of process by which a "best estimate" of the grain-boundary profile is determined. A computer generated profile is convoluted with the X-ray generation function to arrive at a simulated STEM profile, which is then compared with the STEM measurement. The process is iterated until a best fit is achieved using a match between the profile width and depth as criteria. The profile which achieves this best fit is termed the "best estimate" of the grain-boundary composition profile. (b) Schematic of process by which the "best estimate" is compared to the AES measurement. The "best estimate" profile is convoluted with the Auger electron generation function to arrive at a simulated AES measurement which is then compared with the actual AES measurement.

the loss of information about the profile after deconvolution due to propagation of the uncertainty from each data point into all of the surrounding data points. Fig. $8 \mathrm{c}$ shows that more widely spaced data points reduces the oscillations but also reduces the contribution of neighboring data points and hence, minimizes the information gain. In reality, uncertainties of as much as 5 times the amount used in these simulations are often encountered in an individual measurement [14-17], making it impossible to arrive at a solution. Thus, while deconvolution yields a seemingly valid mathematical result, it is an artifact of the finite frequency spectrum used in the deconvolution, hence, there is no correct deconvolution of the noisy data. Another approach, convolution of computer generated profiles with the $\mathrm{X}$-ray generation function, followed by fitting to the measured profiles, may be successful in determining a more accurate representation of the grain-boundary composition, and will be addressed in the following section.

\subsection{Convolution of simulated profiles}

Given that deconvolution does not improve on the accuracy of the measured grain-boundary composition, we consider convolution. If it is possible to find a realistic composition profile that, when convoluted with the average $\mathrm{X}$-ray generation function gives a good fit
UHP+P

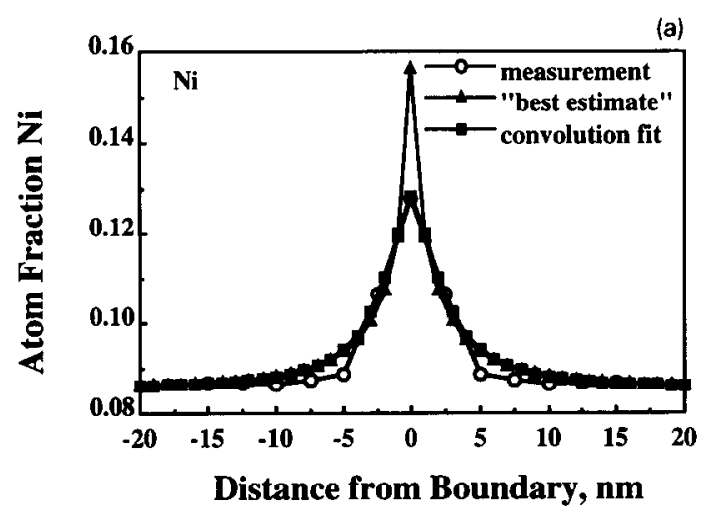

$\mathrm{UHP}+\mathrm{P}$

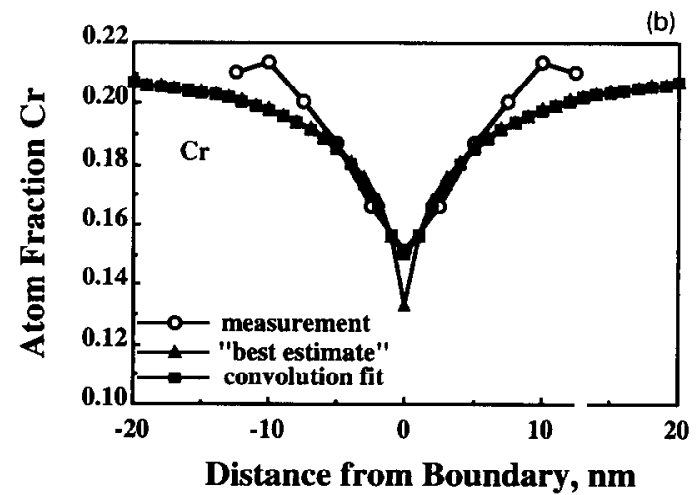

Fig. 10. "Best estimate" profile of (a) Ni and (b) $\mathrm{Cr}$ in UHP $+\mathrm{P}$ and comparison between the STEM measurement and simulated STEM measurement determined by a convolution of the "best estimate" and the X-ray generation function. 
to the measurement, then it would be reasonable to assume that the profile provides a better estimate of the concentration of that element at the grain boundary. A similar procedure has been applied to equilibrium segregation [22]. The procedure begins with the generation of composition profiles using a computer code based on the Perks model [36] of RIS. These "computed" profiles are then convoluted with the average X-ray generation function to yield a simulated STEM profile, and the process is iterated until a best fit to the STEM measurement is achieved in terms of peak height and full width at half maximum. This process is diagrammed in Fig. 9a. The sole criterion for determining input parameters to the code is the agreement between simulated STEM profile and STEM measurement. The profile which yields the best agreement between the simulated STEM profile and the STEM measurement (by visual comparison) is termed the "best estimate" of the actual grain boundary profile. Examples of the measured profile, the "best estimate" of the actual grain boundary profile, and the convolution of the "best estimate" profile with the $\mathrm{X}$-ray generation function in the foil (simulated STEM profile) are shown in Fig. 10 for $\mathrm{Cr}$ and $\mathrm{Ni}$ in the UHP $+P$ alloy. STEM measurements and "best estimate" grain-boundary values for all alloys are given in Table 3 , columns 3 and 5 , respectively.

The "best estimate" profiles appear qualitatively correct because they push the segregation in the expected direction, namely toward higher peak concentrations for $\mathrm{Ni}$ and more depletion for $\mathrm{Cr}$ profiles. However, it must be emphasized that these profiles are at best a subjective fit to the measured profiles and are only semiquantitative. They provide a nonunique fit, that is, a different profile shape may give a fit that could be judged "as good as" the one used in this analysis. The fit is again non-bounded, i.e. it may under- or overestimate the actual concentration of an element at the grain boundary. The comparison of these profile values with the AES measurements in the next section will give an indication of the reliability of these results.

\subsection{Comparison with $A E S$ measuremenis}

The composition at the grain boundary, as measured by AES, is influenced by several factors, among these the depth resolution due to the Auger electron escape depth, $\epsilon_{\mathrm{D}}$. The escape depth is the characteristic length associated with the exponential decay of the Auger electron intensity and is commonly expressed as a thickness in monolayers,

$\epsilon_{\mathrm{D}, i}$ (monolayers) $=\left(538 / E_{i}^{2}+0.41\left(a E_{i}\right)^{0.5}\right) \cos \Theta$,

where $E_{i}$ is the Auger electron energy of element $i$ in $\mathrm{eV}, \cos \Theta$ is a geometrical factor related to the electron escape angle and the acceptance angle of the analyzer [37], and $a$ is the monolayer thickness in $\mathrm{nm}$ as determined by the equation

$a^{3}=(A / \rho n N) \times 10^{21}$.

Here $A$ is the atomic or molecular weight $(\mathrm{g} / \mathrm{mol}), n$ is the number of atoms in the molecule, $N$ is Avagadro's number, and $\rho$ is the density of the material in $\mathrm{g} / \mathrm{cm}^{3}$ [38]. Using average values of $\rho, N$ and $A$ for stainless steel, Eqs. (3) and (4) yield escape depths of 3.6 monolayers for $\mathrm{Cr}, 4.2$ monolayers for $\mathrm{Ni}$ and a monolayer thickness of $0.225 \mathrm{~nm}$. Convoluting the best estimate profile with the Auger electron intensity profile yields

Table 4

Comparison of AES measurements with simulated values (at $\%$ )

\begin{tabular}{|c|c|c|c|c|}
\hline Alloy & $\begin{array}{l}\text { AES } \\
\text { measurement }\end{array}$ & $\begin{array}{l}\text { Simulated AES value } \\
\text { (from convolution using } \\
\text { "best estimate" profile) }\end{array}$ & $\begin{array}{l}\text { Difference between } \\
\text { AES measurement and } \\
\text { its simulated value }\end{array}$ & $\begin{array}{l}\text { Difference between } \\
\text { AES measurement } \\
\text { and STEM measurement }\end{array}$ \\
\hline \multicolumn{5}{|l|}{ UHP } \\
\hline $\mathrm{Cr}$ & $17.2 \pm 0.7$ & 16.9 & 0.3 & 0 \\
\hline $\mathrm{Ni}$ & $12.9 \pm 0.3$ & 11.8 & 1.1 & 1.9 \\
\hline \multicolumn{5}{|c|}{$\mathrm{UHP}+\mathrm{P}$} \\
\hline $\mathrm{Cr}$ & $15.0 \pm 0.4$ & 14.6 & 0.4 & -1.5 \\
\hline $\mathrm{Ni}$ & $13.8 \pm 0.5$ & 13.5 & 0.3 & 1.9 \\
\hline \multicolumn{5}{|c|}{$\mathrm{UHP}+\mathrm{S}$} \\
\hline $\mathrm{Cr}$ & $15.0 \pm 0.5$ & 14.9 & 0.1 & -1.1 \\
\hline $\mathrm{Ni}$ & $15.5 \pm 0.5$ & 11.9 & 3.6 & 3.5 \\
\hline \multicolumn{5}{|c|}{$\mathrm{UHP}+\mathrm{Si}$} \\
\hline $\mathrm{Cr}$ & - & 12.9 & - & - \\
\hline $\mathrm{Ni}$ & - & 14.8 & - & - \\
\hline
\end{tabular}

${ }^{a}$ Errors are given as the standard deviation of the mean, $\sigma / \sqrt{N}$. 
the simulated AES grain-boundary value for element $i$, $C_{i, \mathrm{AES}}$,

$$
\begin{aligned}
C_{i, \mathrm{AES}}= & \frac{\int_{0}^{\infty} I_{i}(x) C_{i}(x) \mathrm{d} x / \int_{0}^{\infty} I_{i}(x) \mathrm{d} x}{\sum_{k}\left[\int_{0}^{\infty} I_{k}(x) C_{k}(x) \mathrm{d} x / \int_{0}^{\infty} I_{k}(x) \mathrm{d} x\right]} \\
& =\frac{\sum_{j} I_{i j} C_{i j} / \sum_{j} I_{i j},}{\sum_{k}\left[\frac{\sum_{j} I_{k j} C_{k j}}{\sum_{j} I_{k j}}\right]} \quad 0 \leq j \leq 20,
\end{aligned}
$$

where $I_{i}(x)$ is the Auger electron intensity profile of element $i, C_{i}(x)$ is the concentration profile of element $i, I_{i, j}$ and $C_{i, j}$ are the respective discretized functions for the $j$ th monolayer and $\Sigma_{k}$ is over all the elements in the alloy. This process is diagrammed in Fig. $9 \mathrm{~b}$.

Simulated AES values, using Eq. 5 with monolayer steps, are given in Table 4 , along with the AES measurement for each alloy. As shown in column 3 , the simulated AES value for $\mathrm{Cr}$ concentration ranges from 12.9 to 16.9 at $\%$, and that for $\mathrm{Ni}$ ranges from 11.8 to 14.8 at $\%$. Four of the six simulated AES values agree with AES measurements to better than 0.4 at $\%$ as shown in column 4 . This compares with the accuracy of the AES measurement as given by the standard deviation of the mean, $0.3-0.7$ at $\%$, indicating that the match between simulation and measurement is within the error of the measurement. This is much better agreement than between AES and STEM measurements (column 5) indicating that the simulated values are much closer to the actual grain-boundary values than are the measurements. The direction of improvement is toward greater segregation in all cases, as expected.

\subsection{Impurities}

The previously described convolution method is not applicable to the impurities of interest because the STEM results indicate that their segregation profiles are significantly narrower than the $X$-ray generation function. In this case, the amount of segregant at the boundary is given by:

$N_{\mathrm{A}}=\frac{C_{\mathrm{M}}}{\left(1-C_{\mathrm{M}}\right)} \frac{1}{b g(0)} \int_{0}^{\infty} g(x) \mathrm{d} x$

monolayers, where $C_{\mathrm{M}}$ is the measured STEM concentration, $g(x)$ is the X-ray generation function and $b$ is the monolayer width. Using $b=0.225 \mathrm{~nm}$ and $C_{\mathrm{M}}=1.4$ at $\% \mathrm{P}$, we obtain $0.14 \pm 0.01$ monolayers. For comparison, our AES measurements yield a measured $P$ concentration of $8.7 \%$. Assuming that segregated $P$ is confined to a monolayer, and that it is split between the two grain surfaces upon intergranular fracture, Eq. (5) can then be used to account for the variation in escape depths, yielding $0.40 \pm 0.036$ monolayers of $P$ at the grain boundary. Attempts to fit the AES data to broader segregation profiles result in even poorer agreement. Thus, the results indicate that the width of the $\mathrm{P}$ segregation profile is of the order of one monolayer.

The large disagreement between the grain-boundary $P$ concentrations derived from AES and STEM indicates the limited accuracy of the information used in the analysis. First, both the AES escape depths and the details of the grain-boundary structure are known only approximately, thus limiting the reliability of the value derived from AES. Second, for a narrow segregation profile, the calculated grain-boundary concentration, as determined from STEM, is very sensitive to errors in the electron beam profile. An important conclusion is that neither STEM nor AES measurements provide the acrual values of the grain-boundary concentrations. While AES measurements, performed under similar conditions, can be used for relative comparison of data obtained by different investigators, such a comparison is less reliable when different STEM instruments are used. We also note that AES data, when analyzed without consideration of the profile width, will yield values that may differ substantially from the actual grain-boundary values.

\section{Recommendations for measurement and analysis}

In order to achieve the best possible estimate of the grain-boundary composition, measurements using both STEM and AES are recommended. STEM measurements provide information about the shape of the segregation profile and also about the degree of segregation at the boundary. These measurements should be made with the smallest possible probe diameter available on the instrument, in the thinnest regions $(\sim 50$ $\mathrm{nm}$ ) of the sample that still provide a high enough $\mathrm{X}$-ray acquisition rate for rapid analysis. Either automatic or frequent manual correction for drift is essential to minimize the loss of spatial resolution. The data should be collected using step sizes which are a fraction of the profile half-width to retain as much information about the segregation profile shape as possible. Multiple measurements should be made at the grain boundary to provide a statistically good measure of this value. This will also eliminate the need for a large number of profiles if the grain-boundary value is of greatest interest. Nevertheless, enough full profiles need to be measured in order to determine the shape of an "average" measured profile for further analysis; typically $3-5$ profiles are sufficient. For noisy data with 
profile widths comparable to the probe diameter, deconvolution cannot yield a correct mathematical solution. However, iterative convolution of calculated profiles with the average X-ray generation function in the solid can provide a better estimate of the actual composition at the boundary.

AES is useful in providing an independent measure of the grain-boundary composition. However, an accurate determination of the concentration of an element at the grain boundary requires accounting for the escape depth of the Auger electrons and its effect on the measured AES values. The composition of many grain boundaries should be measured and averaged for a particular alloy to reduce the effect of boundary-toboundary variability due to differences in boundary segregation or unequal distribution of segregant on the two fracture surfaces. We have found that $\geq 30$ measurements are typically required to limit the standard deviation of the mean to $\leq 0.5$ at $\%$. Criteria should be established for the selection of grain boundaries. Surface contaminants such as oxygen and carbon should be monitored during data acquisition to prevent their signals from corrupting those of the elements of interest in the material under examination.

\section{Conclusions}

- STEM and AES can both be used to measure radiation-induced grain-boundary segregation; however, neither gives the actual boundary concentration directly because of the finite width or depth of the electron probe or finite escape depth of Auger electrons.

- For profile widths comparable to the STEM probe width, noise in the measured data along with the effects of discrete sampling at finite step spacings preclude a determination of the grain-boundary composition profile by deconvolution.

- Convolution of computer-generated RIS profiles with the known average $\mathrm{X}$-ray generation function can be used to produce simulated profiles that are similar in shape to the measured profiles. Iteratively fitting these simulated profiles to the measured profiles allows the determination of a composition profile that provides a "best estimate" of the actual grain-boundary composition.

- That the grain boundary value determined by convolution is a better estimate of the actual grainboundary value than the direct measurement, is verified by comparison between the AES measurement and its simulated value, determined by convolution of the "best estimate" profile with the Auger electron intensity profile. This difference is less than the error in the AES measurement in 4 of 6 cases. Results also show that the grain-boundary chromium level is, on average, lower than that measured by STEM and AES by 2.1 and 1.8 at \%, respectively, and the grain-boundary $\mathrm{Ni}$ composition is, on average, higher than that measured by STEM and AES by 2.3 and 0.3 at $\%$, respectively.

- With the currently available capabilities of data analysis, AES or STEM can only yield a relative comparison of grain-boundary concentrations for nearmonolayer-wide segregation profiles. Our analysis of the $P$ in the UHP $+P$ alloy suggests that $P$ segregation is essentially contained within a single monolayer at the grain boundary.

\section{Acknowledgements}

The authors wish to thank Dr. Peter Andresen of The General Electric Company for providing the sample alloys. We also thank the Michigan Ion Beam Laboratory at the University of Michigan for the use of the irradiation facilities and the assistance of the staff. The Cambridge Surface Facility at the Massachusetts Institute of Technology, the Electron Microbeam Analysis Laboratory and staff at the University of Michigan, and the SHaRE program of the Oak Ridge Associated Universities are acknowledged for their assistance in providing the facilities and support for AES and STEM analysis. The assistance of Dr. D.C. Joy and the use of Monte Carlo routines developed by him for simulating the electron beam-interaction volume were invaluable. Thanks to J. Cookson and T. Allen for their help in performing the irradiations and for many helpful discussions, and to I.A. Charlot and E.P. Simonen for their help in analyses and acquisitions of the data. This research was supported by the Northwest College and University Association for Science (Washington State University) under Grant DE-FG06-89ER-75522 with the US Department of Energy, under contract DEAC05-84OR-21400 with the Division of Material Sciences, Martin Marietta Energy Systems, Inc.; and under contract DE-AC05-76OR-00033 for the SHaRE program, the US Department of Energy under Grant DE-FG07-88ER-12825, and the Division of Basic Energy Sciences of the US Department of Energy under grant DE-FG02-93ER-12130 and contract DE-AC0676RL-01830.

\section{References}

[1] A.J. Jacobs, Grain boundary segregation and IGSCC in cold-worked type 304 stainless steel, paper no. 495, Corrosion / 89 (National Association of Corrosion Engineers, Houston, 1989).

[2] N.Q. Lam, A. Kumar and H. Wiedersich, Proc. 11th Conf. on Effects of Radiation on Materials, ASTM- 
STP782, eds. H.R. Brager and J.S. Perrin, (American Society for Testing and Materials, Philadelphia, 1982) p. 985.

[3] A.L. Bennett, ed., Proc. 10th Int. Symp. on Irradiation Effects on Structural Alloys for Nuclear Reactor Applications, ASTM-STP 484 (American Society for Testing and Materials, Philadelphia, 1970).

[4] G.S. Was and P.L. Andresen, J. Metals 44 (4) (1992) 8.

[5] K. Fukuya, S. Nakahigishi, S. Ozake, M. Terasawa and S. Shima, Proc. 3rd Int. Conf. on Environmental Degradation of Materials in Nuclear Power Systems - Water Reactors, eds. J. Theus and J.R. Weeks (The Minerals, Metals, and Materials Society, Warrendale, 1988) p. 665.

[6] R.H. Jones, Proc. 2nd Int. Conf. on Environmental Degradation of Materials in Nuclear Power Systems Water Reactors, eds. J.T.A. Roberts and J.R. Weeks, (American Nuclear Society, LaGrange Park, 1985) p. 173.

[7] P.L. Andresen and C.L. Briant, Proc. 3rd Int. Conf. on Environmental Degradation of Materials in Nuclear Power Systems - Water Reactors, eds. G.J. Theus and J.R. Weeks (The Minerals, Metals, and Materials Society, Warrendale, 1988) p. 371.

[8] P.L. Andresen, F.P. Ford, S.M. Murphy and J.M. Perks, Proc. 4th Int. Conf. on Environmental Degradation of Materials in Nuclear Power Systems - Water Reactors, ed. D. Cubbicciotti (National Association of Corrosion Engineers, Houston, 1990) p. 1.

[9] D.I.R. Norris, ed., Proc. Radiation Induced Sensitization of Stainless Steels. Central Electricity Generating Board, Berkeley, 1987.

[10] C.S. Pande, M. Suenaga, B. Vyas, H.S. Issacs and D.F. Harling, Scripta Metall. 11 (1977) 681.

[11] G.S. Was, H.H. Tischner and R.M. Latanision, Metall. Trans. 12A (1981) 1397.

[12] K. Asano, K. Nakata, K. Fukuya and M. Kodama, Proc. 5th Int. Conf. on Environmental Degradation of Materials in Nuclear Power Systems - Water Reactors, eds. D. Cubbicciotti and E.P. Simonen (The American Nuclear Society, La Grange Park, 1992) p. 838.

[13] S.M. Bruemmer, B.W. Arey and L.A. Charlot, Proc. Corrosion 91 (National Association of Corrosion Engineers, Houston, 1991) paper no. 38.

[14] A.J. Jacobs, Proc. 16th Symposium on Effects of Radiation on Materials (American Society for Testing and Materials, Philadelphia) in press

[15] C. Shepherd and T.M. Williams, Proc. 4th Int. Conf. on Environmental Degradation of Materials in Nuclear Power Systems - Water Reactors, ed. D. Cubbicciotti (National Association of Corrosion Engineers, Houston, 1990) p. 14-11.

[16] D.I.R. Norris, C. Baker and J.M. Titchmarsh, Proc. Radiation-Induced Sensitization of Stainless Steels, ed. D.I.R.
Norris (Central Electricity Generating Board, Berkeley, 1987) p. 86.

[17] S.M. Bruemmer, L.A. Charlot and E.P. Simonen, Proc. 5th Int. Conf. on Environmental Degradation of Materials in Nuclear Power Systems - Water Reactors, eds. D. Cubbicciotti and E.P. Simonen (The American Nuclear Society, La Grange Park, 1992) p. 821.

[18] E.A. Kenik, J. Nucl. Mater. 187 (1992) 239.

[19] R.D. Carter, D. L Damcott, M. Atzmon, E.A. Kenik and G.S. Was, J. Nucl. Mater. 205 (1993) 361

[20] M. Seah, Vacuum, 36 (7-9) (1986) 399.

[21] C.L. Briant, Acta Metall. 31 (1983) 257.

[22] D.B. Williams and A.D. Romig, Jr., Ultramicroscopy 30 (1989) 38.

[23] A. Partridge and G.J. Tatlock, Surf. Interf. Anal. 18 (1992) 713.

[24] J.F. Ziegler, J.P. Biersack and U. Littmark, The Stopping and Range of Ions in Solids (Pergamon Press, New York, 1984) p. 1.

[25] J.M. Cookson, R.D. Carter, D.L. Damcott, M. Atzmon and G.S. Was, J. Nucl. Mater. 202 (1993) 104.

[26] C.L. Briant, Metall. Trans. 16A (1985) 2061.

[27] L.E. Davis, N.C. MacDonald, P.W. Palmberg, G.E. Riach and R.E. Weber, Handbook of Auger Electron Spectroscopy (Physical Electronics Division, Perkin-Elmer Corporation, Eden Prairie, 1978).

[28] E.A. Kenik, Scripta Metall. 21 (1987) 811.

[29] J.I. Goldstein, in Principles of Analytical Microscopy, eds. D.C. Joy, A.D. Romig and J.I. Goldstein (Plenum, New York, 1986).

[30] C.L. Briant and H.J. Grabke, Mater. Sci. Forum 46 (1989) 253.

[31] C.L. Briant, Metall. Trans. 18A (1987) 691.

[32] W.I. Press, B.P. Flannery, S.A. Teukolsky and W.T. Vetterling, Numerical Recipes (Cambridge University Press, New York, 1987) p. 407.

[33] P.A. Jansson, Deconvolution (Academic Press, Orlando, 1984).

[34] D.C. Joy, Monte Carlo simulations of electron beam-solid interactions, private communication (1992).

[35] J.F. Mansfield and D.C. Crawford, Proc. 12th Int. Conf. for Electron Microscopy, vol. 2, eds. L.D. Peachy and D.B. Williams (San Francisco Press, San Francisco, 1990) p. 504.

[36] J.M. Perks, A.D. Marwick and C.A. English, Proc. Radiation-Induced Sensitization of Stainless Steels, ed. D.I.R. Norris (Central Electricity Generating Board, Berkeley, 1987) p. 15.

[37] M.P. Seah and W.A. Dench, Surf. Interf. Anal. 1 (1979) 2.

[38] G.W.C. Kaye and T.H. Laby, Tables of Physical and Chemical Constants, 14th ed. (Longman, London, 1973). 